УДК 504.064.2.001.18, 550.394.4

\title{
МЕТОДИКА УПРАВЛЕНИЯ РИСКОМ ПРОЯВЛЕНИЯ ОПОЛЗНЕВЫХ ПРОЦЕССОВ С УЧЕТОМ ФАКТОРА СЕЙСМИЧЕСКОЙ АКТИВНОСТИ НА ТЕРРИТОРИИ КИРГИЗСКОЙ РЕСПУБЛИКИ
}

\author{
Романенко Сергей Владимирович1, \\ svr@tpu.ru
}

\section{Ларионова Екатерина Владимировна 1}

Малдыбаев Урмат Амантурович2, urmat_japarov@mail.ru

\author{
Айдаралиев Болотбек Рысбекович2, \\ ktrmc@krsu.edu.kg \\ Ордобаев Бейшенбек Сыдыкбекович², \\ ordobaev@mail.ru \\ 1 Национальный исследовательский Томский политехнический университет, \\ Россия, 634050, г. Томск, ул. Ленина, 30. \\ 2 Киргизско-Российский Славянский университет, \\ Киргизская Республика, 720000, г. Бишкек, ул. Киевская, 44.
}

\begin{abstract}
Актуальность исследования обусловлена необходимостью управления риском активизации оползневых процессов на территории Киргизской Республики, которые наносят ощутимый экономический, экологический и социальный ущерб и приводят к большим человеческим жертвам. Это имеет большое значение для рационального природопользования, обеспечения безопасности населения, объектов экономики и инфраструктуры. Одним из важнейших фракторов формирования оползневых процессов является сейсмическая активность.

Цель: разработать методику управления риском активизации оползневых процессов на основе взаимосвязи между оползневыми процессами и сейсмической активностью на территории Киргизской Республики.

Методы: данные Международного сейсмологического центра и Главного управления Министерства чрезвьчайных ситуаций Киргизской Республики, регрессионный анализ.

Результаты. Предложена методика управления риском на примере риска активизации оползневых процессов в природных условиях Киргизской Республики с учетом фрактора сейсмичности. Методика предполагает оценку риска оползневых процессов, оиенку эфффективности затрат для каждого мероприятия по снижению риска и оиенку срока окупаемости каждого мероприятия. Исходя из срока окупаемости проводится ранжирование мероприятий и определяется эфрфективность каждого мероприятия по снижению риска. Для оценки риска активизации оползневых процессов использовали вероятностностатистический анализ. В работе найдена корреляция зависимости между оползневыми процессами и сейсмической активностью (сумма магнитуд землетрясений), проведен регрессионный анализ. Показано, что наблюдается удовлетворительная линейная корреляция между количеством оползневых процессов и суммой магнитуд землетрясений в период с 1969 по 2010 г2. в Ошской, Жалал-Абадской и Баткенской областях Киргизской Республики. Проведена оценка риска оползневых процессов для села Аскалы Алайского района Ошской области Киргизской Республики. Предложен ряд мероприятий для уменьшения риска оползневых процессов, оценена эфффективность и окупаемость данных мероприятий. Показано, что лесомелиоративную защиту можно считать эфрфективной с точки зрения издержек.
\end{abstract}

\section{Ключевые слова:}

Управление риском, прогнозирование, оползневые процессы, сейсмическая активность, регрессионный анализ, экономическая эфффективность.

\section{Введение}

На территории Киргизской Республики в течение последних десяти лет отмечается существенное возрастание оползневой активности в связи с активизацией взаимодействующих современных геодинамических движений, сейсмичности, подъемом уровня подземных вод, аномальным количеством выпадающих атмосферных осадков, а также инженерно-хозяйственной деятельностью человека, нарушающей баланс устойчивости склона в горных зонах. Оползни на территории Киргизстана осложняют природопользование, приводят к разрушениям жилых домов и инфраструктуры населенных пунктов вследствие их расположения вблизи опасных склонов, представляют угрозу перекрытия русел рек, что сопровождается формированием прорывоопасных плотин запрудных озер, которые, в случае прорыва, несут селе-паводковые бедствия расположенным ниже по руслу реки домам, дорогам, мостам, ЛЭП, хвостохранилищам и другим объектам [1-4].

Для предотвращения ощутимого экономического, экологического, социального ущерба от активизации оползневых процессов необходимо внедрение администрациями регионов совместно с ведомственными и научными организациями процесса управления рисками. Управление риском складывается из следующих этапов, которые чередуются циклически: (пере)оценка риска (прогнозирование), выбор эффективных и экономичных средств нейтрализации рисков. 
Известно достаточно большое число подходов к прогнозированию оползневой опасности, среди которых выделяют локальные и региональные методы, которые делятся на качественный и количественный прогноз. В свою очередь количественные методы прогноза в зависимости от методологии подхода разделяются на детерминированные и вероятностные [4]. В работах [5-7] приведены обзоры методов, применяемых для оценки риска оползневых процессов. В работе [8] показано, что в последние десять лет значительно увеличилось количество публикаций в области прогнозирования оползневых процессов, что связано с развитием и доступностью методов дистанционного зондирования, математического моделирования и технологий ГИС, а также с пониманием администрациями регионов необходимости проведения научных исследований для выявления районов, подверженных повышенному риску оползневых процессов, что поможет более эффективному планированию мероприятий по снижению этих рисков.

Проявление оползневых процессов обусловлено взаимодействием разнообразных факторов, таких как геологическое строение, геоморфологические условия, современные тектонические движения, климатические и гидрогеологические условия, сейсмические процессы и др. Группу факторов, определяющих режимы проявления оползней в краткосрочных глобальных и локальных прогнозах, называют триггерными [6]. Эта группа факторов включает атмосферные осадки и режим их выпадения, температурные условия, изменение уровня подземных вод, притока поверхностных вод, изменение влажности грунта, прочностные и деформационные свойства горных пород, сейсмические проявления (землетрясения), антропогенное воздействие и другие [4].

Несмотря на большое количество используемых подходов, проблему прогнозирования оползневой опасности нельзя считать решенной. Оценка риска оползневых процессов остается сложной проблемой из-за того, что морфологические свойства грунтов и характеристики склона сильно различаются даже на небольших расстояниях, а время, место и интенсивность запуска триггерных факторов трудно прогнозировать [7].

Одним из важнейших факторов формирования оползневых процессов на территории Киргизской Республики является сейсмическая активность [3]. Землетрясения оказывают значительное влияние на устойчивость склонов. При прохождении сейсмической волны возникают инерционные силы, способные увеличивать сдвиговые усилия и тем самым создавать более благоприятные условия для формирования оползней [4].

Цель исследования - разработать методику управления риском активизации оползневых процессов на основе изучения взаимосвязи между оползневыми процессами и сейсмической активностью на территории Киргизской Республики.

\section{Методы}

Для прогнозирования влияния триггерных факторов используют вероятностно-статистические методы.
Среди них достаточно эффективным является нахождение корреляционных и регрессионных зависимостей устойчивости оползневых процессов от различных факторов [4, 7]. В работах Д. Киффера [9, 10] установлена линейная корреляционная связь между общим числом зарегистрированных оползней и сейсмической активностью на территории 650 км², полученная по данным аэрофотосъёмки и полевых исследований. В работах $[11,12]$ приводиться подтверждение и уточнение корреляций, полученных в работах Д Киффера. Логистическая регрессия использовалась при оценке вероятности оползневых процессов при влиянии факторов колебания грунта, топографического фактора, литологии, влажности грунта, количества осадков, растительного покрова, магнитуды землетрясений [13-15]. При детальной характеристике отдельных оползней используются регрессионные зависимости физических характеристик оползня от изменяющихся факторов (амплитуда землетрясения, количество осадков) [16]. В региональном ретроспективном мониторинге находит применение корреляционный анализ зависимостей физических характеристик оползней и величины триггерных факторов от характеристик отдельных землетрясений [17-21].

При проведении вероятностно-статистического анализа требуется большой объем достоверных результатов натурных наблюдений. В Киргизской Республике в последние годы Министерство по чрезвычайным ситуациям (МЧС) совместно с научно-исследовательскими организациями активно развивает систему сбора статистических данных об опасных явлениях и процессах, которая имеет не только практическое, но и научнопрогностическое значение [1]. Полученные данные могут быть использованы для развития вероятностностатистических методов оценки краткосрочных рисков оползневых процессов в рамках экономикогеографических регионов Киргизской Республики для получения общего представления о подверженности территории страны оползневым процессам.

В работе были использованы данные «Международного сейсмологического центра» [22] по магнитуде землетрясений, произошедших в исследуемых районах Киргизской Республики и данные МЧС Киргизской Республики по количеству оползневых процессов в различных районах Киргизии с 1969 по 2010 гг. Эффективность противооползневых мероприятий оценивали экспертным путем [23]. Для обработки полученных зависимостей количества оползневых процессов от магнитуды землетрясений использовали регрессионный анализ с помощью программы Statistica 8.0 [24].

\section{Результаты и их обсуждение}

Наибольшее распространение оползневые процессы получили на юге Киргизской Республики. Развитие и квазипериодическая активизация оползневых процессов на юге страны связаны с особенностями и сочетанием оползнеобразующих геологических и климатических факторов: наличием слабоустойчивых горных склонов, имеющих геофильтрационное строение и рыхлый поверхностный чехол (лёсс, лёссовид- 
ные суглинки) мощностью в десятки метров; повышенной сейсмотектонической активностью региона; сезонным переувлажнением грунтов, слагающих склоны за счет интенсивных и обильных атмосферных осадков, снеготаяния и периодического повышения уровней грунтовых и подземных вод [4].
Как видно из рис. 1, в Ошской области доля оползневых процессов достигает $51,5 \%$ от общего числа чрезвычайных ситуаций, в Жалал-Абадской области - $29 \%$, в Баткенской области - 16,6 \%, что свидетельствует о значимости оползневых процессов в данных областях.

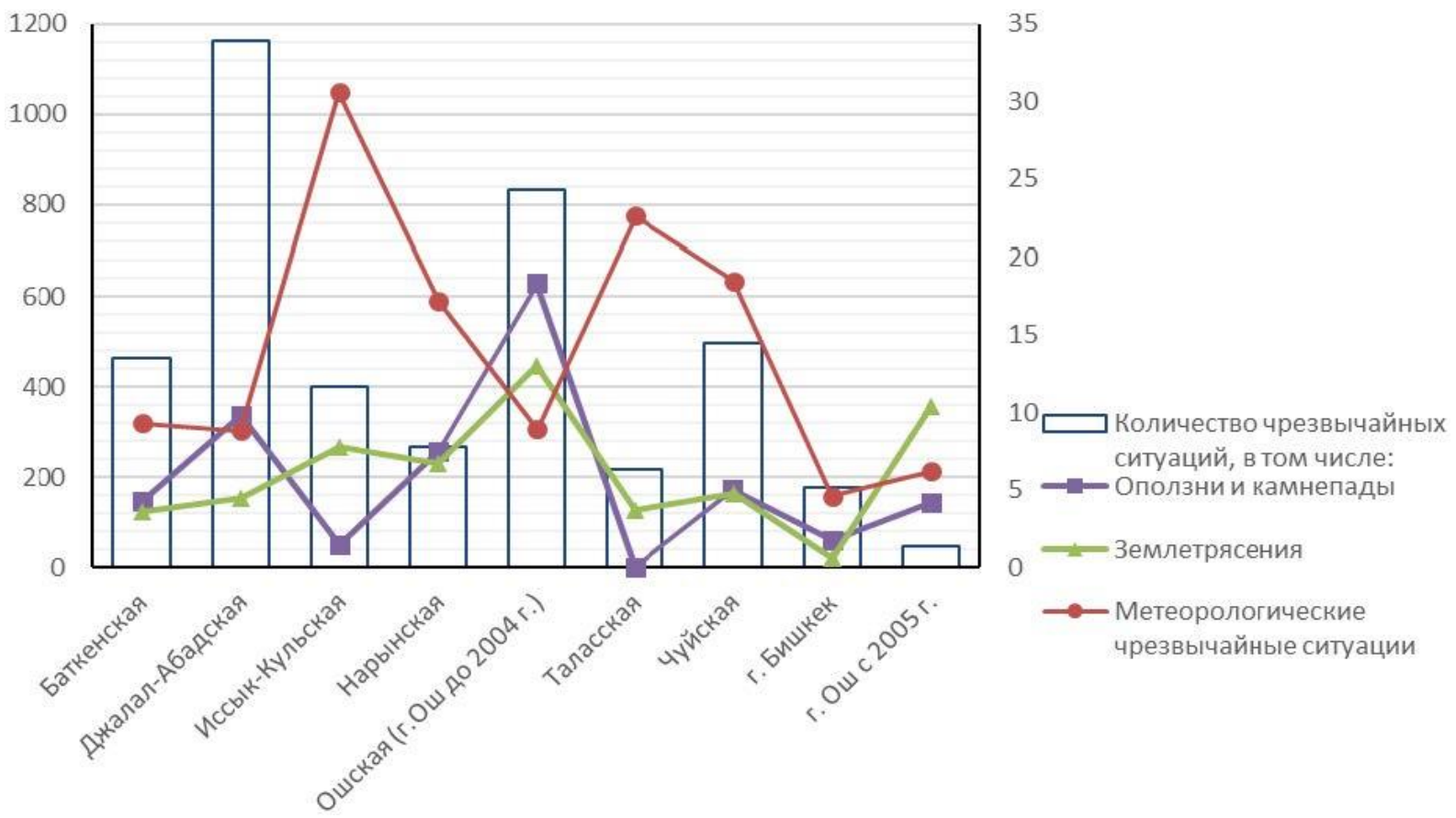

Рис. 1. Количество зарегистрированных чрезвычайных ситуаций, связанных с основными видами опасных природных и техногенных проиессов за 2000-2016 г2. на территории административных областей Киргизской Республики

Fig. 1. Number of emergencies related to natural and man-made processes for 2000-2016 in the territory of the administrative authority of the Kyrgyz Republic

В работе рассмотрена корреляция между количеством оползневых процессов и сейсмической активностью в период с 1969 по 2010 гг. в Алайском, Сузакском и Лейлекском районах, расположенных соответственно в Ошской, Жалал-Абадской и Баткенской областях. В качестве показателя сейсмической активности использовали сумму магнитуд землетрясений выше 4, имеющих эпицентры в исследуемых районах, в течение года, учитывая, что землетрясения с магнитудой ниже 4 практически не приводят к активизации оползневых процессов, а на расстоянии более $10 \mathrm{kм}^{2}$ от эпицентра землетрясения плотность оползней составляет менее одного на км ${ }^{2}[17,19]$.

На рис. 2 приведены зависимости количества оползней от суммы магнитуд землетрясений в трех районах Ошской, Жалал-Абадской и Баткенской областях. В табл. 1 приведены результаты линейного регрессионного анализа зависимостей, представленных на рис. 2. Как показано в табл. 1, нулевые гипотезы о линейности не отклоняются и принимаются альтернативные гипотезы о значимости угла наклона линейной модели. Таким образом, наблюдается статистически значимая корреляция между количеством оползней и сейсмической активностью. Отметим, что для исследуемой корреляции в случае ЖалалАбадской области свободный коэффициент линейной модели значимо отличается от нуля, поскольку нулевая гипотеза о значимости свободного коэффициента не отклонена, что необходимо учитывать при оценке количества оползневых процессов.

Используя данные о районировании Киргизской Республики по сейсмической опасности и полученные выше зависимости, можно оценить риск оползневых процессов на исследуемых территориях.

Следующим этапом процесса управления рисками является введение мероприятий по снижению риска и оценка их экономической эффективности. Для определения экономической эффективности мероприятий по снижению риска используют различные подходы и критерии в зависимости от отрасли управления рисками: охрана труда [25], экологическая безопасность [26], производственная безопасность [27].

В данной работе нами предложена общая методология оценки экономической эффективности мероприятий по снижению риска. В случае если вероятность возникновения неблагоприятного события может быть определена (для отдельного неблагоприятного события, однотипных событий, группы событий и т. д.), величину риска $R_{i}$ (индивидуального, группового или суммарного) можно оценить как произведение вероятности данного события $\left(P_{i}\right)$ на величину принесенного (прямого или косвенного) ущерба $Y_{i}$ : 


$$
R_{i}=P_{i} Y_{i} \text {. }
$$

Размерность риска в этом случае будет [деньги]/[ед. времени], например [р./Г], а экономический смысл величины риска заключается в скорости возникновения убытков.

Вероятность оползневых процессов можно оценить, используя полученные нами регрессионные зависимости количества оползневых процессов от годовой суммы магнитуд землетрясения. Таким обра-
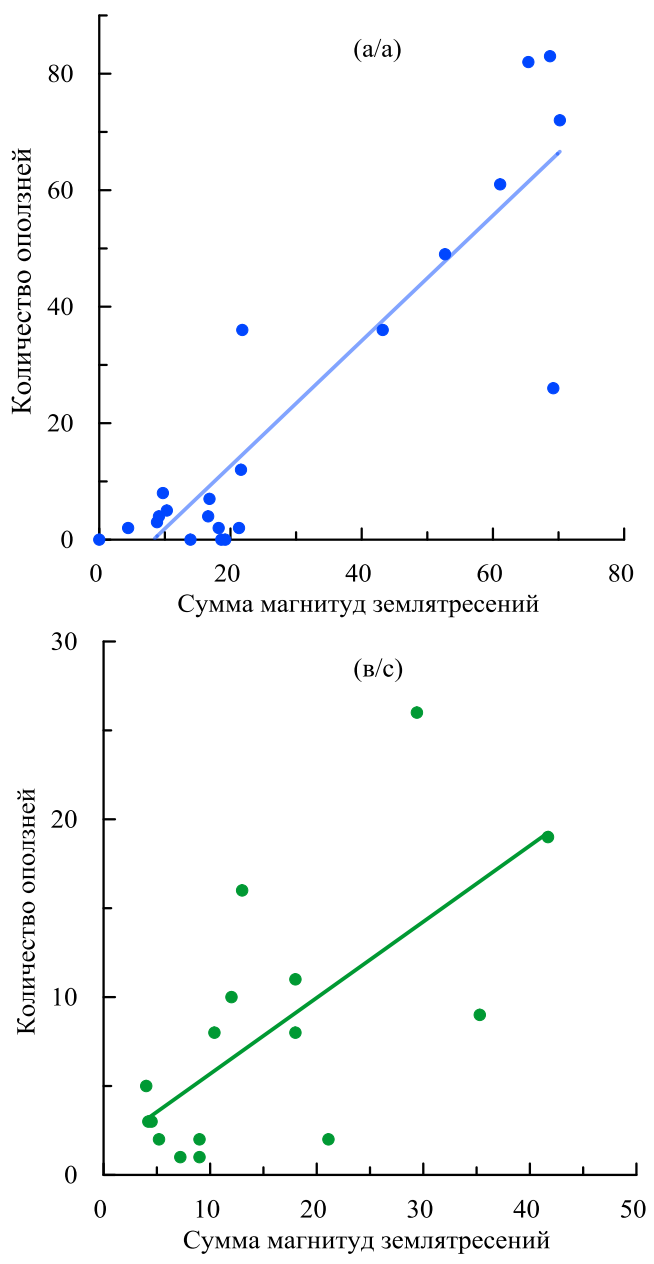

зом, групповой риск проявления оползневых процессов на некоторой территории можно определить как величину:

$$
R=b M Y,
$$

где $b$ - угол наклона регрессионной зависимости между сейсмической активностью и интенсивностью оползневых процессов; $M$ - сумма магнитуд землетрясений в этом районе в течение года.

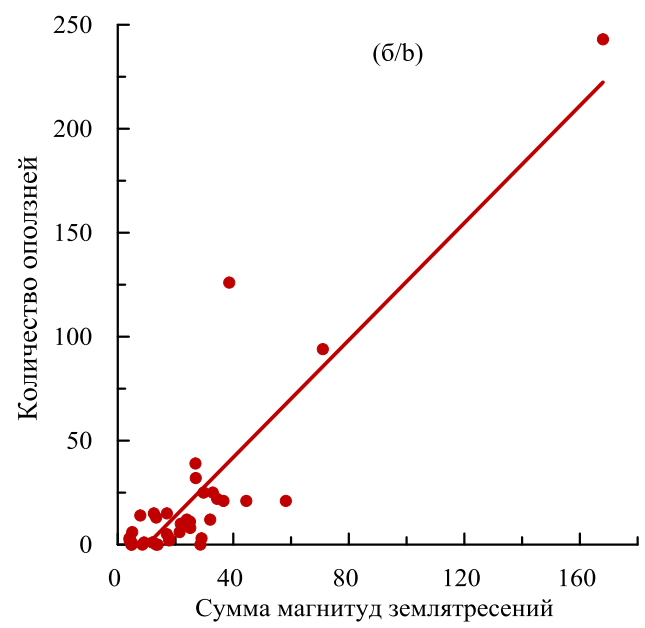

Pис. 2. Корреляция между сейсмической активностью и оползневыми прочессами на территории Алайского района Ошской области (а), Сузакского района Жалал-Абадской области (б) и Лейлекского района Баткенской области (в) Киргизской Республики в 1969-2010 г2.

Fig. 2. Correlation between seismic activity and landslide processes in the Alai region of Osh region (a), Suzak region of Jalal-Abad region (b) and Leilek region of Batken region (c) of Kyrgyzstan in 1969-2010

Таблица 1. Результаты регрессионного анализ данных, представленных на рис. 2

\begin{tabular}{|c|c|c|c|}
\hline $\begin{array}{l}\text { Коэффициенты модели } \\
\text { Regression coefficients }\end{array}$ & $\begin{array}{c}\text { Оценка коэффициентов мо- } \\
\text { дели } \\
\text { Estimation of regression coef- } \\
\text { ficients }\end{array}$ & $\begin{array}{c}\text { Стандартная } \\
\text { ошибка } \\
\text { Standard error }\end{array}$ & $\begin{array}{c}\text { Значение } p \text { для гипотезы о } \\
\text { значимости коэффициентов модели } \\
p \text { value for hypothesis of significance of re- } \\
\text { gression coefficients }\end{array}$ \\
\hline \multicolumn{4}{|c|}{$\begin{array}{c}\text { Алайский район Ошской области/Alai region of Osh region } \\
{ }^{1} r=0,89220512 ; \text { гипотеза о линейности/hypothesis test for linearity: } p<0,00000 ; \text { стандартная ошибка/standard error: } 13,332\end{array}$} \\
\hline Свободный член/Intercept & -9 & 5 & 0,06514 \\
\hline Наклон/Line slope & 1,1 & 0,1 & $2,43 \times 10^{-8}$ \\
\hline \multicolumn{4}{|c|}{$\begin{array}{c}\text { Сузакский район Жалал-Абадской области/Suzak region of Jalal-Abad region } \\
r=0,89106831 ; \text { гипотеза о линейности/hypothesis test for linearity: } p<0,00000 ; \text { стандартная ошибка/standard error: } 20,496\end{array}$} \\
\hline Свободный член/Intercept & -14 & 5 & 0,002941 \\
\hline Наклон/Line slope & 1,4 & 0,1 & $6,57 \times 10^{-14}$ \\
\hline \multicolumn{4}{|c|}{$\begin{array}{l}\text { Лейлекский район Баткенской области/Leilek region of Batken region } \\
\text { линейности /hypothesis test for linearity: } p<0,00366 \text {; стандартная ошибка/standard error: 5,4911 }\end{array}$} \\
\hline Свободный член/Intercept & 1 & 2 & 0,552727 \\
\hline Наклон/ Line slope & 0,4 & 0,1 & 0,003662 \\
\hline
\end{tabular}

Table 1. Results of regression analysis of the data presented in Fig. 2

${ }^{l} r$ - коэффициент корреляции/correlation coefficient, $p$ - достигнутый уровень значимости/achieved significance level, фиксированный уровень значимости равен 0,05/fixed significance level is equal to 0,05. 
По данным МЧС Киргизской Республики оползневые процессы охватывают около $20 \%$ территории Алайского района Ошской области [2]. На примере с. Аскалы Алайского района покажем методологию оценки риска оползневых процессов и эффективности противооползневых мероприятий. В соответствии с картой районирования по сейсмической опасности [1] с. Аскалы Алайского района находится в Гульчинской зоне ожидаемых землетрясений - третьей категории опасности с классом ожидаемых землетрясений 12-15, интенсивностью 6-7 баллов.

Определим размер ущерба как сумму выплат и компенсации при возникновении оползневых процессов для жителей с. Аскалы. Примем, что на территории села расположены 12 жилых домов в среднем по 3 жителя в каждом доме, итого 36 человек; категория выплат: III категория, 1001 расчётных показателей Киргизской Республики [28]. Один расчетный показатель равен 100 сомов=103 руб. [29, 30]. Таким образом, размер ущерба составляет:

$$
Y=36 \times 1001 \times 103=3711708 \mathrm{p} .
$$

Примем, что сейсмичность составляет 7 баллов повторяемостью 3 раза в год, итого 21 балл [1]. Оценка риска оползневых процессов по формуле (1) будет составлять:

$$
R=1,1 \times 21 \times 3711708=85740455 \mathrm{p} . / \text { год. }
$$

Для снижения риска оползневых процессов в выбранном селе введем ряд противооползневых мероприятий [23]:

1. Противооползневые дренажи.

2. Изменение баланса грунтовых масс на оползневом склоне. Контрбанкеты.

3. Лесомелиорация.

Дренирование подземных вод применяется в целях устранения воздействия на породы, образующие оползневый склон, снижения или полного снятия гидростатического и гидродинамического напоров, уменьшения дебита подземных вод еще до их подхода к оползневому склону, удаления подземных вод, выклинивающихся на поверхность. Изменение баланса грунтовых масс и контрбанкеты применяются с целью улучшения распределения напряжений, испытываемых породами оползневого склона, и образования искусственного рельефа, отвечающего требованиям повышения общей и частной устойчивости склона и планировки оползневого района, перемещением больших и малых масс грунта. Лесомелиорация применяется для закрепления поверхностей оползневых склонов древесно-кустарниковой растительностью, посевом трав и одерновкой [23].

Размер эффективных затрат $\left(E_{Z, j}\right)$ (конкретного мероприятия) определяется как:

$$
E_{Z, j}=Z_{j} / K_{R, j},
$$

где $Z_{j}$ - затраты для конкретного мероприятия; $K_{R, j}$ коэффициент эффективности для конкретного мероприятия (оценивается экспертным путем).

Трудность восприятия «эффективных затрат» заключается в том, что, имея размерность [деньги], они могут быть равны (при максимальной эффективности мероприятия, т. е. полного исключения риска) или больше (при не полном исключении риска, а снижении вероятности его проявления и/или уменьшения ущерба) фактических (необходимых) затрат на рассматриваемое мероприятие. В этом смысле увеличение «эффективных затрат» по сравнению с фактическими будет корректировать (удлинять) срок окупаемости при неполной эффективности мероприятий.

Оценим окупаемость мероприятий. Срок окупаемости мероприятий $T_{j}$ по снижению риска $R$ определяется как:

$$
T_{j}=E_{Z, j} / R[\text { ед. времени], }
$$

где $E_{Z, j}$ - размер эффективных затрат (2). Под окупаемостью конкретного мероприятия мы понимаем тот период времени, через который ожидаемые издержки (связанные с риском) превысят затраты на предлагаемое мероприятие.

В табл. 2 приведена оценка сроков окупаемости предложенных противооползневых мероприятий рас-

\begin{tabular}{|c|c|c|c|c|c|}
\hline $\begin{array}{c}\text { Мероприятия } \\
\text { по снижению риска } \\
\text { Activities for risk reduction }\end{array}$ & $\begin{array}{c}\text { Затраты на ме- } \\
\text { роприятия [23], } \\
Z_{j} \text { p. } \\
\text { Costs of activities } \\
\text { [23], } Z_{j}, \text { rubles } \\
\end{array}$ & $\begin{array}{c}\text { Коэффициент } \\
\text { эффективности } \\
\text { затрат, } K_{R, j} \\
\text { Coefficient of effec- } \\
\text { tiveness of cost, } K_{R, j}\end{array}$ & $\begin{array}{c}\text { Эффектные } \\
\text { затраты, } E_{Z, j} \text { p. } \\
\text { Effective ex- } \\
\text { penses, } E_{Z, j} \\
\text { rubles }\end{array}$ & $\begin{array}{c}\text { Срок окупае- } \\
\text { мости, } T_{j}, \text { лет } \\
\text { Payback time, } \\
T_{j}, \text { years } \\
\end{array}$ & $\begin{array}{c}\text { Ранжирование } \\
\text { по окупаемости } \\
\text { Payback ranking }\end{array}$ \\
\hline $\begin{array}{l}\text { Противооползневые } \\
\text { дренажи } \\
\text { Landslide control drainage }\end{array}$ & 4060799 & 0,4 & 10151998 & 0,118 & III \\
\hline Контрбанкеты/Counterberm & 381523 & 0,6 & 635872 & 0,007 & II \\
\hline $\begin{array}{l}\text { Лесомелиорация } \\
\text { Forest reclamation }\end{array}$ & 182668 & 0,7 & 260955 & 0,003 & I \\
\hline
\end{tabular}
считанных по (3).

Таблица 2. Оиенка затрат и окупаемости противооползневых мероприятия

Table 2. Evaluation of the costs and payback of landslide prevention works

Таким образом, наиболее эффективным по окупаемости мероприятием можно считать лесомелиоративную защиту. При этом после внедрения мероприятия может быть сделан перерасчет риска с тем, чтобы можно было оценить эффективность очередного мероприятия по его снижению.

\section{Заключение}

В работе предложена методика управления риском на примере риска активизации оползневых процессов в природных условиях Киргизской Республики с учетом фактора сейсмичности. Методика предполагает оценку риска оползневых процессов с учетом влия- 
ния амплитуды землетрясений, оценку эффективности затрат для каждого мероприятия по снижению риска и оценку срока окупаемости каждого мероприятия. Исходя из срока окупаемости проводится ранжирование мероприятий и определяется эффективность каждого мероприятия по снижению риска. Процесс управления риском может быть проведен циклично до снижения риска до приемлемого уровня.

Для оценки риска оползневых процессов в данной работе предложено использовать корреляцию зависимости между количеством оползневых процессов и сейсмической активностью. Для увеличения прогностической достоверности предложенной корреляционной зависимости оценки рисков оползневых процессов необходимо учитывать влияние других триг-

\section{СПИСОК ЛИТЕРАТУРЫ}

1. Мониторинг, прогнозирование опасных процессов и явлений на территории Кыргызской Республики. - Бишкек: Изд-во МЧС КР, 2017. $-743 \mathrm{c}$

2. Ибатулин Х.В. Мониторинг оползней Кыргызстана. - Бишкек: Изд-во МЧС КР, 2011. - 145c.

3. Предупреждение рисков от оползней в Центральной Азии Б.Д. Молдобеков, Ш.Э. Усупаев, У.А. Абдыбачаев, Х.В. Ибатулин, А.К. Сарногоев, М. Абдрахманов, А.В. Мелешко // Известия КГТУ им. Н.Раззакова. - 2014. - Т. 33. - С. 435-439.

4. Фоменко И.К. Методология оценки и прогноза оползневой опасности: дис. ... д-ра наук. - М., 2014. - 309 с.

5. A review of engineering landslide prevention and control / S. Wu, T. Wang, J. Shi, L. Shi, P. Xin // Geological Bulletin of China. 2013. - V. 32. - № 12. - P. 1871-1880.

6. A review of statistically-based landslide susceptibility models / P. Reichenbach, M. Rossi, B.D. Malamud, M. Mihir, F. Guzzetti // Earth-Science Reviews. - 2018. - V. 180. - P. 60-91.

7. Keefer D.K., Larsen M.C. Assessing landslide hazards // Science. - 2007. - V. 316. - P. 1136-1138

8. Analysis and evaluation of landslide susceptibility: a review on articles published during 2005-2016 (periods of 2005-2012 and 2013-2016) / H.R. Pourghasemi, Z. Teimoori Yansari, P. Panagos, B. Pradhan // Arabian Journal of Geosciences. - 2018 - V. 11. № 9. - P. 1-12

9. Keefer D.K. Investigating landslides caused by earthquakes - a historical review // Surveys in Geophysics. - 2002. - V. 23. P. 473-510

10. Keefer D.K. Landslides generated by earthquakes: immediate and long-term effects // Treatise on Geomorphology: Tectonic Geomorphology. - San Diego: Academic Press, 2013. - V. 5. P. 250-266.

11. Malamud B.D., Turcotte D.L., Guzzetti F., Reichenbach. P Landslides, earthquakes and erosion // Earth Planet. Sci. Letters. 2004. - V. 229. - P. 45-59.

12. Rodriguez C.E., Bommer J.J., Chandler R.J. Earthquake-induced landslides: 1980-1997 // Soil Dyn Earthq Eng. - 1999. - V. 18. № 5. - P. 325-346.

13. A global empirical model for near-real-time assessment of seismically induced landslides / M.A. Nowicki Jessee, M.W. Hamburger, K. Allstadt, D.J. Wald, S.M. Robeson, H. Tanyas, E.M. Thompson // Journal of Geophysical Research: Earth Surface. - 2018. - V. 123. - № 8. - P. 1835-1859.

14. Development of a globally applicable model for near real-time prediction of seismically induced landslides / M.A. Nowicki, D.J. Wald, M.W. Hamburger, M. Hearne, E.M. Thompson // Engineering Geology. - 2014. - V. 173. - P. 54-65.

15. A global slope unit-based method for the near real-time prediction of earthquake-induced landslides / H. Tanyas, M. Rossi, M. Alvioli, C.J. van Westen, I. Marchesini // Geomorphology. 2019. - V. 327. - P. 126-146. герных факторов, таких как, например, количество осадков, температурные условия, изменение уровня подземных вод, антропогенное воздействие и др.

Управление риском оползневых процессов на уровне администраций регионов позволит установить приемлемый режим природопользования, разработать и внедрить программы устойчивого развития регионов Киргизской Республики, проводить природоохранные мероприятия и инженерную защиту объектов социально-экономической инфраструктуры и природно-территориальных систем Киргизской Республики.

Предложная методика может быть использована для управления риском возникновения опасностей в различных сферах деятельности человека.

16. Торгоев И.А. Система мониторинга оползней в Кыргызстане // Технологии гражданской безопасности. - 2013. - Т. 10. № 4 (38). - C. 68-71.

17. Keefer D.K. Statistical analysis of an earthquake-induced landslide distribution - the 1989 Loma Prieta, California event // Engineering Geology. - 2000. - V. 58. - № 3-4. - P. 231-249.

18. Chen Xiaoli, Liu Chunguo. Complex seismic focus structure and earthquake-triggered landslide distribution: analysis of the 2014 Ludian Mw6.1 Earthquake in Yunnan // Acta Geologica Sinica. 2017. - V. 91. - № 2. - P. 733-734.

19. Geometrical characteristics of earthquake-induced landslides and correlations with control factors: A case study of the 2013 Minxian, Gansu, China, Mw 5.9 event / Y. Tian, C. Xu, J. Chen, Q. Zhou, L. Shen // Landslides. - 2017. - V. 14. - № 6. - P. 1915-1927.

20. Xu C., Xu X. Statistical analysis of landslides caused by the Mw 6.9 Yushu, China, earthquake of April 14, 2010 // Natural Hazards. - 2014. - V. 72. - № 2. - P. 871-893.

21. The size, distribution, and mobility of landslides caused by the 2015 Mw7.8 Gorkha earthquake / K. Roback, M.K. Clark, A.J. West, D. Zekkos, G. Li, S.F. Gallen, D. Chamlagain, J.W. Godt // Nepal Geomorphology. - 2018. - V. 301. - P. 121-138.

22. Международный сейсмологический центр. URL: http://www.isc.ac.uk/ (дата обращения 25.02.2019).

23. Инженерная защита территорий, зданий и сооружений от оползней. Основные положения, нормы и правила / Б.Р. Айдаралиев, Б.С. Ордобаев, Р.С. Супаналиев, Н.Дж. Садабаева, М. Атамбек уулу. - Бишкек: КРСУ, 2014. - 199 с.

24. Боровиков В.П. STATISTICA. Искусство анализа данных на компьютере. 2-е изд. - СПб.: Питер, 2003. - 688 с.

25. Сердюк В.С., Бакико Е.В. Экономика безопасности труда. Омск: ОмГТУ, 2011. - 160 с.

26. РД 03-496-02. Методические рекомендации по оценки ущерба от аварий на опасных производственных объектах. - М.: ЭС НТИ «Техэксперт», 2004. - 37 с.

27. Об исчислении и взимании платы за негативное воздействие на окружающую среду: Постановление Правительства РФ от 03.03.2017 г. № 255. URL: http://government.ru/docs/26694/ (дата обращения 10.04.2020).

28. Об утверждении Классификации чрезвычайных ситуаций и критериев их оценки в Кыргызской Республике: Постановление Правительства Кыргызской Республики от 22 ноября 2018 года № 550. URL: http://cbd.minjust.gov.kg/act/view/ru-ru/12747 (дата обращения 10.04.2020).

29. О расчетном показателе: Закон Кыргызской Республики от 27 января 2006 года № 13: Принят Жогорку Кенешем Кыргызской Республики 8 декабря 2005 г. URL: http://cbd.minjust. gov.kg/act/view/ru-ru/1801 (дата обращения 10.04.2020).

30. Об утверждении размера расчетного показателя: Постановление Жогорку Кенеша Кыргызской Республики от 15 июня 2006 года № 1115-III. URL: http://cbd.minjust.gov.kg/ act/view/ru-ru/51948 (дата обращения 10.04.2020). 
Информация об авторах

Романенко С.B., доктор химических наук, профессор Исследовательской школы химических и биомедицинских технологий Национального исследовательского Томского политехнического университета.

Ларионова Е.B., кандидат химических наук, доцент Исследовательской школы химических и биомедицинских технологий Национального исследовательского Томского политехнического университета.

Малдыбаев У.А., аспирант Киргизско-Российского Славянского университета.

Айдаралиев Б.P., директор учебного научно-технического центра «Развитие гражданской защиты» КиргизскоРоссийского Славянского университета.

Ордобаев Б.C., кандидат технических наук, профессор, заведующий кафедрой защиты в чрезвычайных ситуациях Киргизско-Российского Славянского университета. 
UDC 504.064.2.001.18, 550.394.4

\title{
RISK MANAGEMENT TECHNIQUE OF LANDSLIDES ACTIVATION WITH ACCOUNT OF SEISMIC ACTIVITY FACTOR IN KYRGYZSTAN
}

\author{
Sergey V. Romanenko', \\ svr@tpu.ru
}

\author{
Ekaterina V. Larionova 1 \\ Urmat A. Muldybaev², \\ urmat_japarov@mail.ru \\ Bolotbek R. Aydaraliev², \\ ktrmc@krsu.edu.kg \\ Beishenbek S. Ordobaev2, \\ ordobaev@mail.ru \\ 1 National Research Tomsk Polytechnic University, \\ 30, Lenin avenue Tomsk, 634050, Russia. \\ 2 Kyrgyz-Russian Slavic University, \\ 44, Kievskaya avenue, Bishkek, 720000, Kyrgyzstan.
}

The relevance of the research is caused by the need to manage the risk of landslide processes in Kyrgyzstan, which cause significant economic, environmental and social damage and lead to great loss of life. This is of great importance for sustainable use of natural resources, ensuring the safety of the population, economic and infrastructure facilities. One of the most important factors in the formation of landslide processes is seismic activity.

The main aim of the research is to develop a risk management methodology for the activation of landslide processes based on the relationship between landslide processes and seismic activity in the Kyrgyzstan.

Methods: data of International Seismological Center and Main Directorate of Ministry of Emergencies of Kyrgyzstan, regression analysis. Results. A risk management technique is proposed on the example of the risk of landslide activation in the natural conditions of Kyrgyzstan, taking into account the seismicity factor. The methodology involves assessing the risk of landslide processes, evaluating the costeffectiveness of each activities to reduce risk, and evaluating the payback period of each measure. Based on the payback period, the ranking of activities is carried out and the effectiveness of each risk reduction activities is determined. To assess the risk of landslide activation, statistical analysis was used. In this work the correlation of the relationship between landslide processes and seismic activity (the sum of the magnitudes of earthquakes) was found, a regression analysis was performed. It was shown that a satisfactory linear correlation is observed between the number of landslide processes and the sum of earthquake magnitudes from 1969 to 2010 in the Osh, Jalal-Abad and Batken regions of Kyrgyzstan. The risk of landslide processes was assessed for the village of Askaly, Alai district, Osh region of Kyrgyzstan. A number of activities are proposed to reduce the risk of landslide processes, the effectiveness and payback of these activities is evaluated. It is shown that forest reclamation protection can be considered effective in terms of costs.

\section{Key words:}

Risk management, prediction, landslide processes, seismic activity, regression analysis, economic efficiency.

\section{REFERENCES}

1. Monitoring, prognozirovanie opasnykh protsessov i yavleniy na territorii Kyrgyzskoy Respubliki [Monitoring, forecasting hazardous processes and phenomena in the territory of Kyrgyzstan] Bishkek, MCHS KR Publ., 2017. 743 p.

2. Ibatulin H.V. Monitoring opolzney Kyrgyzstana [Monitoring landslides in Kyrgyzstan]. Bishkek, MCHS KR Publ., 2011. 145 p.

3. Moldobekov B.D., Usupaev Sh.E., Abdybachaev U.A., Ibatulin H.V., Sarnogoev A.K., Abdrahmanov M., Meleshko A.V. Preduprezhdenie riskov ot opolzney v Tsentralnoy Azii [Prevention of landslide risks in Central Asia]. Izvestiya KGTU im. N Razzakova, 2014, vol. 33, pp. 435-439.

4. Fomenko I.K. Metodologiya otsenki i prognoza opolznevoy opasnosti. Diss. Dokt. nauk [The landslide hazard assessment and forecast methodology. Dr. Diss.]. Moscow, 2014. 309 p.

5. Wu S., Wang T., Shi J., Shi L., Xin P. A review of engineering landslide prevention and control. Geological Bulletin of China, 2013, vol. 32, no. 12, pp. 1871-1880

6. Reichenbach P., Rossi M., Malamud B.D., Mihir M., Guzzetti F. A review of statistically-based landslide susceptibility models. Earth-Science Reviews, 2018, vol. 180, pp. 60-91.
7. Keefer D.K., Larsen M.C. Assessing landslide hazards. Science, 2007, vol. 316, pp. 1136-1138.

8. Pourghasemi H.R., Teimoori Yansari Z., Panagos P., Pradhan B. Analysis and evaluation of landslide susceptibility: a review on articles published during 2005-2016 (periods of 2005-2012 and 2013-2016). Arabian Journal of Geosciences, 2018, vol. 11 (9), pp. 1-12.

9. Keefer D.K. Investigating landslides caused by earthquakes - a historical review. Surveys in Geophysics, 2002, vol. 23, pp. 473-510.

10. Keefer D.K. Landslides generated by earthquakes: immediate and long-term effects. Treatise on Geomorphology: Tectonic Geomorphology. San Diego, Academic Press, 2013. Vol. 5, pp. 250-266.

11. Malamud B.D., Turcotte D.L., Guzzetti F., Reichenbach P. Landslides, earthquakes and erosion. Earth Planet. Sci. Letters, 2004, vol. 229, pp. 45-59.

12. Rodriguez C.E., Bommer J.J., Chandler R.J. Earthquake-induced landslides: 1980-1997. Soil Dyn Earthq Eng., 1999, vol. 18, no. 5, pp. 325-346.

13. Nowicki Jessee M.A., Hamburger M.W., Allstadt K., Wald D.J., Robeson S.M., Tanyas H., Thompson E.M. A global empirical model for near-real-time assessment of seismically induced land- 
slides. Journal of Geophysical Research: Earth Surface, 2018, vol. 123 , no. 8, pp. 1835-1859.

14. Nowicki M.A., Wald D.J., Hamburger M.W., Hearne M., Thompson E.M. Development of a globally applicable model for near real-time prediction of seismically induced landslides, Engineering Geology, 2014, vol. 173, pp. 54-65.

15. Tanyas H., Rossi M., Alvioli M., van Westen C.J., Marchesini I. A global slope unit-based method for the near real-time prediction of earthquake-induced landslides. Geomorphology, 2019, vol. 327, pp.126-146.

16. Torgoev I.A. Landslide monitoring system in Kyrgyzstan. Civil Security Technology, 2013, vol. 10, no. 4 (38), pp. 68-71. In Rus.

17. Keefer D.K. Statistical analysis of an earthquake-induced landslide distribution - the 1989 Loma Prieta, California event. Engineering Geology, 2000, vol. 58, no. 3-4, pp. 231-249.

18. Chen Xiaoli, Liu Chunguo. Complex seismic focus structure and earthquake-triggered landslide distribution: analysis of the 2014 Ludian Mw6.1 Earthquake in Yunnan. Acta Geologica Sinica, 2017, vol. 91, no. 2, pp. 733-734.

19. Tian Y., Xu C., Chen J., Zhou Q., Shen L. Geometrical characteristics of earthquake-induced landslides and correlations with control factors: A case study of the 2013 Minxian, Gansu, China, Mw 5.9 event. Landslides, 2017, vol. 14, no. 6, pp. 1915-1927.

20. Xu C., Xu X. Statistical analysis of landslides caused by the Mw 6.9 Yushu, China, earthquake of April 14, 2010. Natural Hazards, 2014, vol. 72, no. 2, pp. 871-893.

21. Roback K., Clark M.K., West A.J., Zekkos D., Li G., Gallen S.F., Chamlagain D., Godt J.W. The size, distribution, and mobility of landslides caused by the 2015 Mw7.8 Gorkha earthquake. Nepal Geomorphology, 2018, vol. 301, pp. 121-138.

22. International seismological center. Available at: http://www.isc.ac.uk/ (accessed 25 February 2019).

23. Ajdaraliev B.R., Ordobaev B.S., Supanaliev R.S., Sadabaeva N.Dzh., Atambek uulu M. Inzhenernaya zashchita territoriy, zdaniy $i$ sooruzheniy ot opolzney. Osnovnye polozheniya, normy i pravila [Engineering protection of territories, buildings and struc- tures from landslides. Basic provisions, norms and rules]. Bishkek, KRSU Publ., 2014. 199 p.

24. Borovikov V.P. STATISTICA. Iskusstvo analiza dannykh na kompyutere [The art of computer data analysis]. St-Petersburg, Piter Publ., 2003. 688 p.

25. Serdyuk V.S., Bakiko E.V. Ekonomika bezopasnosti truda [Labor safety economics]. Omsk, OmGTU Publ., 2011. 160 p.

26. RD 03-496-02. Metodicheskie rekomendatsii po otsenke ushcherba ot avariy na opasnykh proizvodstvennykh obektakh [Guidelines for assessing damage from accidents at hazardous production facilities]. Moscow, ES NTI «Tekhekspert» Publ., 2004. 37 p.

27. Ob ischislenii i vzimanii platy za negativnoe vozdeystvie na okruzhayushchuyu sredu [On the calculation and collection of fees for negative environmental impact]. Postanovlenie Pravitelstva RF ot 03.03.2017 g. № 255. Available at: http://government.ru/ docs/26694/ (accessed 10 April 2020).

28. Ob utverzhdenii Klassifikatsii chrezvychaynykh situatsiy $i$ kriteriev ikh otsenki v Kyrgyzskoy Respublike [On approval of the Classification of emergency situations and criteria for their assessment in the Kyrgyz Republic]. Postanovlenie Pravitelstva Kyrgyzskoy Respubliki ot 22 noyabrya 2018 goda № 550. Available at: http://cbd.minjust.gov.kg/act/view/ru-ru/12747 (accessed 10 April 2020).

29. Raschetnom pokazatele [About estimated indicator]. Zakon Kyrgyzskoy Respubliki ot 27 yanvarya 2006 goda № 13. Available at: http://cbd.minjust.gov.kg/act/view/ru-ru/1801 (accessed 10 April 2020).

30. Ob utverzhdenii razmera raschetnogo pokazatelya [On approval of the size of the calculated indicator]. Postanovlenie Zhogorku Kenesha Kyrgyzskoy Respubliki ot 15 iyunya 2006 goda № 1115 III. Available at: http://cbd.minjust.gov.kg/act/view/ru-ru/51948 (accessed 10 April 2020).

Received: 15 April 2020.

\section{Information about the authors}

Sergey V. Romanenko, Dr. Sc, professor, National Research Tomsk Polytechnic University.

Ekaterina V. Larionova, Cand Sc., associate professor, National Research Tomsk Polytechnic University.

Urmat A. Muldybaev, undergraduate student, Kyrgyz-Russian Slavic University.

Bolotbek R. Aydaraliev, director of the educational scientific and technical center «Development of Civil Protection», Kyrgyz-Russian Slavic University.

Beishenbek S. Ordobaev, Cand. Sc., head of the department, Kyrgyz-Russian Slavic University. 